\section{Why choose us?}

Howden Insurance Brokers strives to deliver products and services you can rely on when you need them most. So, why choose us?

\section{$\rightarrow$ Policies tailored for all career stages}

- from students to those approaching retirement

$\rightarrow$ Contract certainty - no discretionary cover here, providing total confidence that we will defend you whenever you need us

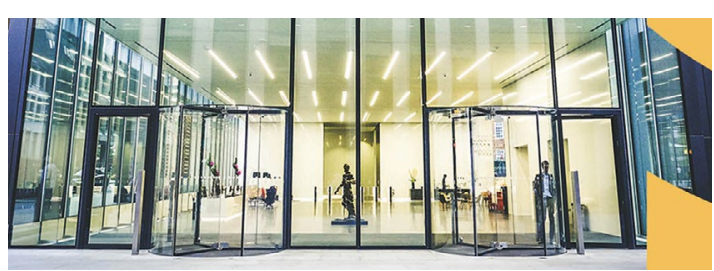

$\rightarrow 10$ years run off - full run off discovery period of 10 years is provided, including claims following death, permanent disablement or retirement

$\rightarrow$ Commercial and professional cover - we provide dental indemnity and insurance for your practice

$\rightarrow$ Dedicated account handler - so you always work with the same person who knows you and your situation well.

For more details, bespoke advice or a free, no obligation quote, visit www.howdengroup. co.uk or call 02076233806 .
Overcome complex \section{endodontic challenges}

In complex cases it can seem easier to extract a tooth - but what if it could be saved? At EndoCare, we specialise in helping patients to keep their natural dentition and, by using the latest techniques and methods, we always do our absolute best to solve any complex endodontic cases.

We aim for providing as pain-free as possible treatment, and this aids us in helping those with dental phobia and anxiety. We also always let patients listen to music or watch films when in our practice, helping to soothe their nerves and ensure they are comfortable and happy.

Once we've treated your patients, we will return them to you with full details of any treatment given and our aftercare steps. Let's overcome complex challenges together.

For further information call EndoCare on 02072240999 or visit www.endocare. co.uk. and Dentistry Show Birmingham will be held on Friday 13 and Saturday 14 May 2022, Birmingham NEC, co-located with DTS. For more information, visit birmingham.dentistryshow.co.uk, or email dentistry@closerstillmedia.com.
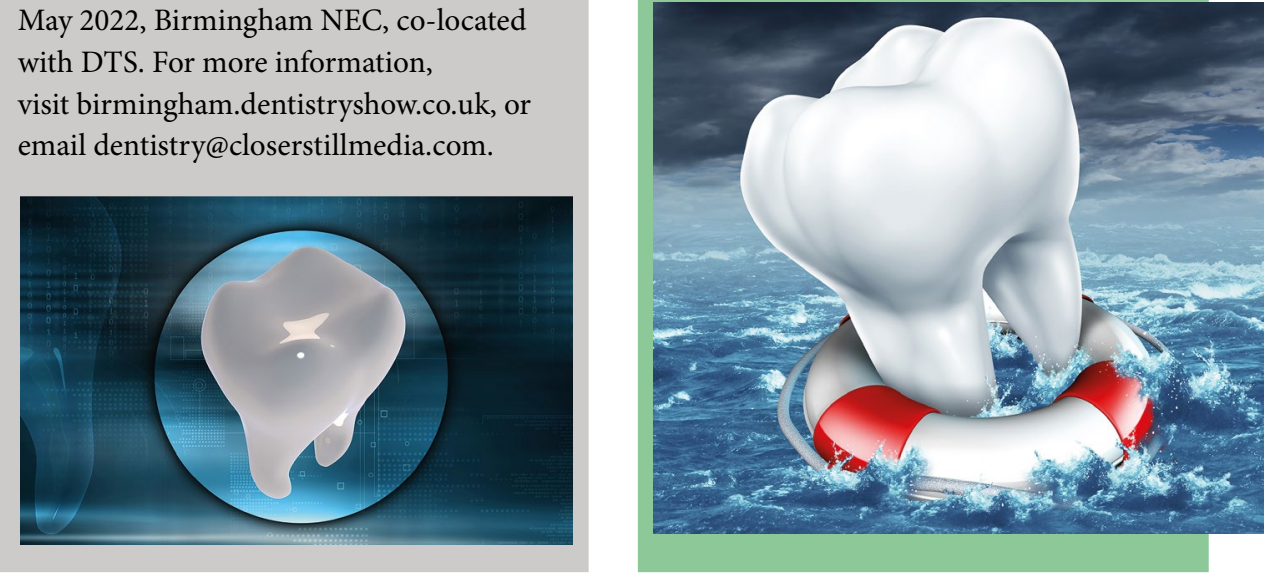

\title{
Protecting from caries
}

Curasept Biosmalto from J\&S Davis is an innovative solution for the effective management and prevention of dental caries - as well as tooth wear, dry mouth, white spots, fluorosis, sensitivity and molar demineralisation.

It consists of an innovative formula that contains substituted hydroxyapatite, which enables rapid remineralisation benefits while protecting the teeth from further damage through acid erosion, acid attacks, mechanical abrasion and sensitivity.

It offers the flexibility of both

in-practice and at-home application,

helping clinicians deliver added value to their patients.

For more information on the industryleading products available from J\&S Davis, visit www.js-davis.co.uk, call 01438747344 or email jsdsales@js-davis.co.uk.
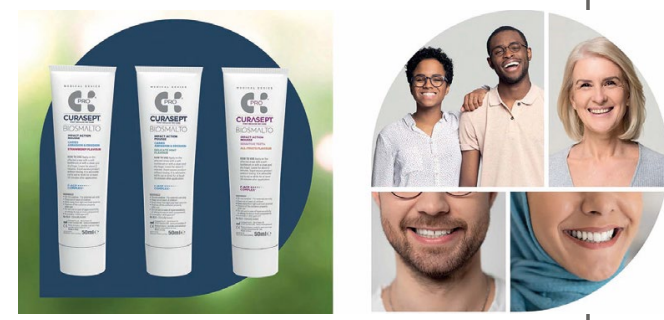